\title{
COMPARISON OF LEARNING OUTCOMES IN PROBLEM BASED LEARNING AND LECTURE BASED LEARNING IN TEACHING FORENSIC MEDICINE
}

\author{
Krishnan Balendran ${ }^{1}$, Liza John² \\ ${ }^{1}$ Assistant Professor, Department of Forensic Medicine, Government T. D. Medical College, Alappuzha. \\ ${ }^{2}$ Associate Professor, Department of Forensic Medicine, Government T. D. Medical College, Alappuzha.
}

ABSTRACT
BACKGROUND
A paradigm shift in the medical education methodologies from traditional methods to the SPICES model necessitates a change in
teaching and assessment techniques. A call for change has to be accepted or rejected in the face of quality research and peer
reviewed evidence.

\section{METHODS}

The present study was undertaken amongst third semester MBBS students posted in Forensic Medicine as a part of clinical rotations. Two groups of students were instructed on a topic by Problem based learning and traditional lecture based learning respectively. Post-exposure assessments were undertaken using a peer reviewed and validated question paper (open ended questions). The results of the assessment were subjected to statistical analysis with respect to the various levels of cognitive domain.

\section{RESULTS}

The results showed statistically significant learning outcomes in the group exposed to Problem based learning. The study may be done on a broader basis representing core area of the subject.

\section{CONCLUSION}

The study brought out statistically significant better assessment scores in the problem based learning method, which was manifest not only in recall but also in the higher levels of the cognitive domain. The learning process also witnessed an appreciably increased level of student co-operation and team work coupled with greater problem solving skills amongst the learners. A qualitative research into assessing the competence of the Indian Medical Graduate to fulfil his legal duties as a medical expert witness in courts of law may be undertaken in future.

\section{KEYWORDS}

Problem Based Learning, Learning Outcome, Forensic Medicine.

HOW TO CITE THIS ARTICLE: Balendran K, John L. Comparison of learning outcomes in problem based learning and lecture based learning in teaching forensic medicine. J. Evolution Med. Dent. Sci. 2017;6(2):89-92, DOI: 10.14260/Jemds/2017/22

\section{BACKGROUND}

In 1910, Flexner introduced a medical education technique in which both basic and clinical sciences used the scientific method. In the 1980s, this method was criticised for being too "horizontal" and "vertical" (that is to say, divided into independent compartments with no integration).(1) Traditional medical education disenchanted students who perceived the vast amount of material in the first three years of medical school as having little relevance to clinically based medicine and its practice. The problem based learning was pioneered in the Medical School program at McMaster University in Hamilton, Ontario, Canada in order to stimulate and assist the learners in seeing the relevance of learning to future roles, maintain a higher level of motivation towards learning, and to show the learners the importance of

Financial or Other, Competing Interest: None.

Submission 30-11-2016, Peer Review 24-12-2016,

Acceptance 30-12-2016, Published 05-01-2017.

Corresponding Author:

Dr. Krishnan Balendran,

Department of Forensic Medicine,

Government T. D. Medical College,

Vandanam P. O., Alappuzha.

E-mail: krishnanbalendran@gmail.com

DOI: $10.14260 /$ jemds $/ 2017 / 22$ responsible professional attitudes.(2)Problem based learning (PBL) is defined in modern day pedagogy in medical education as the scientific instructional method where "triggers" are used to define customised learning objectives, perform independent research, refine and analyse findings in group discussions. (3)

In the conventional lecture based curriculum, relatively little emphasis was placed on critical analysis, self-directed learning or problem solving. The new trends in medical education focus on acquisition of skills, knowledge and attitudes rather than factual learning. Problem analysis and decision making towards its solution are key skills in the practice of medicine and research.(4) PBL curriculum aims to inculcate the above-mentioned abilities in medical students and to promote self-directed lifelong learning.

Problem based learning is a departure from the traditional lecture based learning method. Problem based learning has been adopted as an educational strategy which assists and guides the learner from theory to practice during their journey through solving the problem.(5) Implementation of any new educational strategy has to be based on evidence. The present study to compare Problem Based Learning with Lecture Based Learning was undertaken to clarify the impact of new teaching methods on our student's knowledge and their skills at problem solving. 


\section{Aims and Objectives}

- To compare the learning outcomes in Forensic Medicine using lecture based learning and problem based learning.

- To assess the impact of problem based learning on the various levels of cognitive domain like recall, analysis and application.

\section{MATERIALS AND METHODS}

The study was conducted on the third semester students of Govt. TD Medical College, Alappuzha.

An interventional study was done with convenient sampling. The students who were posted in the Department of Forensic Medicine as part of their third semester clinical rotation were the subjects of study. After due clearance from the Institutional Ethics committee, the study was conducted in the Department of Forensic Medicine. After taking informed consent, a batch of 13 students who were posted in the department was subjected to problem based learning. The students were explained about how problem based learning is conducted and the case based scenario was given to them. They were further divided into subgroups and asked to prepare the various aspects of odollam poisoning like appearance of plant, chemical nature of toxin, mechanism of action, fatal dose, autopsy features, and treatment principles. The students then presented the topic after a preparation period of four days and the presentation was moderated by the faculty. A peer reviewed test was administered which consisted of questions addressing the various levels of knowledge domain like recall, analysis and comprehension and application. Another group of thirteen students who were posted in the next batch was taught odollam poisoning using a traditional lecture based learning and the test administered. The classes were facilitated and conducted by the same teacher. Evaluation of the answer sheets were done using a key prepared during validation of the question paper. The marks were charted depending on the type of question in to three groups based on the level of knowledge as recall, analysis and application. The marks were then analysed statistically using Analysis of Variance to observe the statistical significance of the comparison of Problem based learning and traditional Lecture based learning.

\section{RESULTS AND OBSERVATIONS}

The present study favoured problem based learning with the average marks in each category being significantly higher in PBL.

\begin{tabular}{|c|c|c|c|}
\hline \multicolumn{2}{|c|}{} & $\begin{array}{c}\text { Problem Based } \\
\text { Learning }\end{array}$ & $\begin{array}{c}\text { Lecture Based } \\
\text { Learning }\end{array}$ \\
\hline \multirow{3}{*}{ Recall } & Mean & 30.15 & 13.92 \\
\cline { 2 - 4 } & Median & 31.50 & 13.00 \\
\cline { 2 - 4 } & Variance & 31.308 & 3.577 \\
\hline
\end{tabular}

\begin{tabular}{|c|c|c|c|}
\hline & Std. Deviation & 5.595 & 1.891 \\
\hline & Std. Error Mean & 1.552 & .525 \\
\hline & Minimum & 21 & 12 \\
\hline & Maximum & 38 & 18 \\
\hline & Range & 17 & 6 \\
\hline \multirow{8}{*}{ Analysis } & Mean & 15.31 & 8.38 \\
\hline & Median & 15.00 & 8.00 \\
\hline & Variance & 13.397 & 6.256 \\
\hline & Std. Deviation & 3.660 & 2.501 \\
\hline & Std. Error Mean & 1.015 & 0.694 \\
\hline & Minimum & 9 & 3 \\
\hline & Maximum & 20 & 12 \\
\hline & Range & 11 & 9 \\
\hline \multirow{8}{*}{ Application } & Mean & 21.62 & 16.69 \\
\hline & Median & 22.00 & 16.00 \\
\hline & Variance & 14.756 & 26.231 \\
\hline & Std. Deviation & 3.841 & 5.122 \\
\hline & Std. Error Mean & 1.065 & 1.420 \\
\hline & Minimum & 13 & 8 \\
\hline & Maximum & 26 & 27 \\
\hline & Range & 13 & 19 \\
\hline \multicolumn{4}{|c|}{$\begin{array}{l}\text { Table 1. Descriptive Statistics in Problem } \\
\text { Based and Lecture Based Learning }\end{array}$} \\
\hline
\end{tabular}

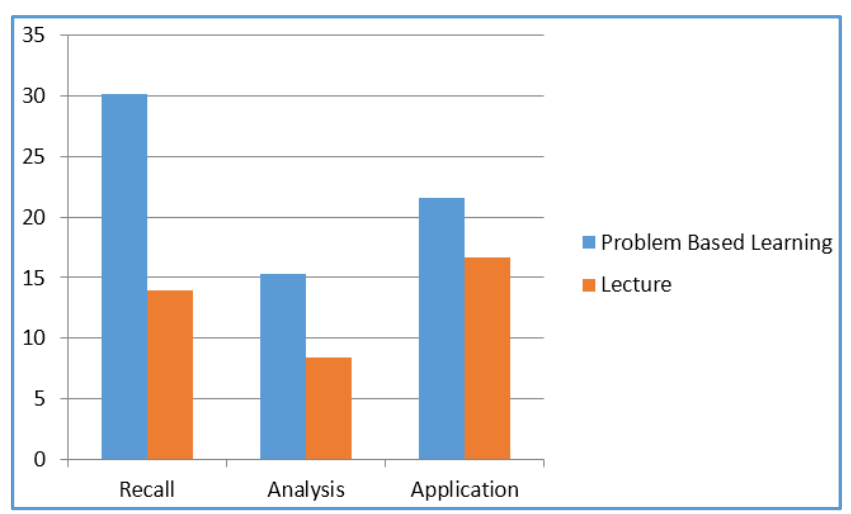

Figure 1. Graph showing Mean Marks Obtained by Problem Based Learning and Lecture Based Learning

Problem based learning and lecture based learning were compared on the criterion of the various levels of knowledge with A null hypothesis that there was no difference in the distribution of marks in both methods of learning was initiated. Independent samples test (Mann Whitney U Test) was done and the null hypothesis was rejected with the PBL group showing higher grades which were statistically significant.

\begin{tabular}{|c|c|c|c|c|}
\hline & Null Hypothesis & Test & Sig. & Decision \\
\hline 1 & $\begin{array}{c}\text { The distribution of Recall is the same across } \\
\text { categories of Group }\end{array}$ & $\begin{array}{c}\text { Independent-Samples Mann- } \\
\text { Whitney U Test }\end{array}$ & 0.000 & Reject the null hypothesis \\
\hline 2 & $\begin{array}{c}\text { The distribution of Analysis is the same across } \\
\text { categories of Group }\end{array}$ & $\begin{array}{c}\text { Independent-Samples Mann- } \\
\text { Whitney U Test }\end{array}$ & 0.000 & Reject the null hypothesis \\
\hline 3 & $\begin{array}{c}\text { The distribution of Application is the same } \\
\text { across categories of Group }\end{array}$ & $\begin{array}{c}\text { Independent-Samples Mann- } \\
\text { Whitney U Test }\end{array}$ & 0.019 & Reject the null hypothesis \\
\hline
\end{tabular}

Asymptotic significances are displayed. The significance level is .05. 


\section{DISCUSSION}

This study shows a definite advantage of problem based learning (PBL) when compared to lecture based learning (LBL) in equipping the learner with factual recall in addition to problem solving skills. This is in conformity with most of the previous studies regarding Problem based learning a few of which have been quoted below. In a study by Tack on dental students in the Netherlands, students' knowledge turned out to be higher in the topic chosen for PBL.(6) According to study conducted by Moreno PBL participants obtained higher scores when compared with LBL group.(7) A study conducted by Anyaehie in Nigeria also indicated that PBL increased students attendance, participation in classes and performance in examinations. (8) Hwang in an investigation to compare PBL and LBL determined that the level of knowledge in the PBL group was significantly higher than that of students in the LBL group.(9)Meo assessed knowledge and skills of undergraduate medical students and concluded that students in PBL group obtained significantly higher scores compared to LBL approach.(10) Student satisfaction was perceived to be higher with PBL in several studies $(9,6)$

Some studies have not been able to identify statistically significant advantage of PBL and have identified outcomes of similar nature with PBL and LBL. This could be due to variety of reasons including poor understanding and implementation of the technique of PBL by both teacher and learner, and superior and exhaustive nature of the lecture. Smits P.B. concluded that both PBL and LBL were equally effective in improving knowledge levels.(11) Carrero compared PBL with LBL and found no significant differences in knowledge.(12) Goodyear showed that learning outcomes were similar in both LBL and PBL.(13) Khan compared the effect of PBL and LBL on the knowledge and attitude and found that both groups demonstrated similar level of knowledge.(14) Johnston undertook a randomised control trial comparing PBL and LBL and concluded that PBL was less effective at imparting knowledge than customary LBL.(15)

Studies by Schmidt (1989) have demonstrated that during problem analysis in a small group and studying the problem with relevance to new information resulted in increased knowledge acquisition and recall.(16) Choi compared PBL with LBL and revealed that learning outcomes of PBL were not statistically different from LBL although students in PBL group showed improved abilities in problem solving, self-directed learning and critical thinking.(1) Meanwhile, McParland compared PBL with LBL and concluded that performance of students in PBL was better in Multiple Choice Questions and Viva but with no differences between the two in learning style and attitude of students.(17) PBL as an educational strategy is an effective tool to objectively improve the knowledge acquisition in medical teaching.(18)

The present study which compared problem based learning and the traditional lecture based method brought out significantly better learning outcomes in the former. This extended to the higher levels of the Cognitive domain. The active discussion of the learners, their independent and collective thinking of anticipated common practical scenarios and questions in the future, discussion with the facilitator during the consolidation phase has been a major factor in the superior scores obtained in the Problem based method. The answers obtained during the discussions have given this group a head start in the assessment. There was also the added advantage of the triggers by different individuals in the group stimulating a sense of competitiveness and urge to excel in each individual which also have contributed to the better collective learning outcome.

\section{CONCLUSION}

The study compared learning outcomes in Forensic Medicine when the topic was instructed in problem based learning and traditional lecture based learning methods. It has brought out statistically significant better assessment scores in the problem based learning method, which was manifest not only in recall but also in the higher levels of the cognitive domain. The learning process also witnessed an appreciably increased level of student co-operation and team work coupled with greater problem solving skills amongst the learners. The study confirms that the shift to the methodology of problem based learning from the traditional is for good reason and thus backs up with evidence the move of the MCI to make changes in the direction of competency based medical education.

\section{Implications}

With the Medical Council of India aiming for a curriculum focussing on competency based medical education, and greater time being allotted for group learning and selflearning activities, the teaching schedule has to change to incorporate more of problem based learning. With more evidence forthcoming that problem based learning leads to better learning outcomes than the traditional lecture based teaching, there is no doubt as to the way forward. Problem based learning is faculty intensive and requires more man hours from the faculty and therefore the recent reduction in the staff pattern poses a challenge to the proper implementation of problem based learning. Integrated teaching and e-learning could address some of these concerns.

Forensic medicine is essentially application of medical knowledge in solving legal problems. Therefore, problem solving skills, aptitude to analyse and comprehend facts presented, and proper presentation of opinions by the medical expert are non-negotiable and vital aspects in so far as administration of Justice is concerned. The teaching of Forensic Medicine has to take problem based learning as the main method of the teaching learning process. Meticulous planning should be undertaken to identify areas where this methodology is most suited, keeping in mind the learning objectives of the subject and assessment methods aligned with the objectives, which is the need of the hour.

I consider that similar studies into assessing the learning outcomes in Practical Forensic documentation report writings in Clinical Forensic Medicine (wound certification, drunkenness examination and medical examination in sexual offences) should be undertaken, preferably with larger sample sizes without constraints of time and other logistics. This could be in addition to undertaking with Qualitative research incorporating all stake holders into the perceptions and issues of utility and quality of medicolegal reports prepared currently in contemporary times. 


\section{Acknowledgements}

Grateful to Mr. Sony Simon, Lecturer in Statistics, Travancore

Medical College, Kollam for statistical support.

\section{REFERENCES}

[1] Choi E, Lindquist R, Song Y. Effects of problem based learning vs traditional lecture on Korean nursing students critical thinking, problem solving, and selfdirected learning. Nurse Educ Today 2014;34(1):52-6.

[2] Barrows HS. Problem based learning in medicine and beyond: a brief overview. New directions for teaching and learning 1996;68:3-12.

[3] Wood Diana F. ABC of learning and teaching in medicine: problem based learning. BMJ 2003;326(7384):328-30.

[4] Birgegard G, Lindquist U. Change in student attitudes to medical school after the introduction of problembased learning in spite of low ratings. Med Educ1998;32(1):46-9.

[5] Edens KM. Preparing problem solvers for the $21^{\text {st }}$ century through problem based learning. College teaching 2000;48(2):55-60.

[6] Tack CJ, Plasschaert AJ. Student evaluation of a problem-oriented module of clinical medicine within a revised dental curriculum. Eur J Dent Educ 2006;10(2):96-102.

[7] Moreno-Lopez LA, Somacarrera-Perez ML, Diaz Rodriguez MM, et al. Problem based learning versus lectures: a comparison of academic results and time devoted by teachers in a course on dentistry in special patients. Med Oral Patol Oral Cir Bucal 2009;14(11):e583-7.

[8] Anyaehie US, Nwobodo E, Njoku CJ, et al. Comparative evaluation of active learning and the traditional lectures in physiology: a case study of 200 level medical laboratory students of Imo state university, Owerri. Niger J Physiol Sci 2007;22(1-2):117-21.
[9] Hwang SY, Kim MJ. A comparison of problem-based learning and lecture-based learning in an adult health nursing course. Nurse Educ Today 2006;26(4):315-21.

[10] Meo SA. Evaluating learning among medical students in schools with traditional and problem-based curricula. Adv Physiol Educ 2013;37(3):249-53.

[11] Smits PB, de Buisonje CD, Verbeek JH, et al. Problembased learning versus lecture-based learning in postgraduate medical education. Scand J Work Environ 2003;29(4):280-7.

[12] Khoshnevisasl P, Sadeghzadeh M, Mazloomzadeh S, et al. Comparison of problem-based learning with lecture-based learning. Iran Red Crescent Med J 2014;16(5):e5186.

[13] Goodyear HM. Problem based learning in a junior doctor teaching programme. Arch Dis Child 2005;90(3):275-8.

[14] Khan H, Taqui AM, Khawaja MR, et al. Problem-based versus conventional curricula: influence on knowledge and attitudes of medical students towards health research. PLos One 2007;2(7):e632.

[15] Johnston JM, Schooling CM, Leung GM. A randomizedcontrolled trial of two educational modes for undergraduate evidence-based medicine learning in Asia. BMC Med Educ 2009;9:63.

[16] Schmidt HG, Volder ML, Grave WS, et al. Explanatory models in the processing of science text: the role of prior knowledge activation through small group discussion. Journal of Educational Psychology 1988;81(4):610-9.

[17] McParland M, Noble LM, Livingston G. The effectiveness of problem-based learning compared to traditional teaching in undergraduate psychiatry. Med Educ 2004;38(8):859-67.

[18] Preeti B, Ashish A, Shriram G. Problem based learning (PBL)-an effective approach to improve learning outcomes in medical training. J Clin Diagn Res 2013;7(12):2896-2897. 